\title{
G
}

COUNTERFUTURES

Left thought \& practice Aotearoa

FIVE

2018 


\title{
Rejuvenating radical potential through transdisciplinarity: Art and public health
}

\author{
Jenny Ombler and Sarah Donovan
}

$\mathbf{P}$

UBLIC HEALTH, AS both a societal goal and a disciplinary endeavour, is facing problems that resist simple solutions. ${ }^{1}$ These so-called 'wicked problems' are hugely complex. While threatening the betterment of health and wellbeing, they reach far beyond the immediate concerns of public health. Climate change, in particular, will affect all human and earthly life, threatening environmental systems and biodiversity, food

1 This paper stems from the symposium Art and Public Health: Wellbeing, Social Critique, and Communication, held on February 24, 2017 as part of the Public Health Summer School held annually at the University of Otago, Wellington (see Jenny Ombler and Sarah Donovan, 'What does art have to do with public health, and how can they work together?' Public Health Expert Blog, April 10, 2018, https://blogs.otago.ac.nz/pubhealthexpert/2017/04/10/what-does-art-have-to-dowith-public-health-and-how-can-they-work-together/). We would like to acknowledge Philippa Howden-Chapman, Michael Baker, Nick Wilson, Nevil Pierse, and our colleagues in the Public Health Department at the University of Otago, Wellington, for encouraging us to do this work. 
production and water availability, economic systems, habitability of land, and the maintenance of peace. These impacts have vast health implications, including rising and unpredictable infectious disease epidemics, hunger, and insecurity. Bound up in this challenge is burgeoning social and socio-economic inequality, both a driver and effect of climate change. The complex and entwined nature of these problems calls into question the already contested ability of politics, government, and society to deliver equitable and healthful outcomes within status quo economics and governance systems. In the context of these wicked problems, we mount an argument for transdisciplinary engagement and action, particularly on the issue of climate change. ${ }^{2}$

Transdisciplinarity is an approach that embraces complexity, openness, and productive collaboration while resisting the impulse to narrow our views to specific disciplines and concerns. Transdisciplinarity differs from 'multi-disciplinary' in that it represents a deeper commitment to traversing the bounds of disciplines, beyond merely 'working together'.

Public health, as a diverse discipline (and one familiar with slow and often circuitous progress in its attempts to address complex issues), has a proclivity to foster lateral thinking. Nonetheless, it is a field that is also vulnerable to closing itself to

2 With thanks to Anne Noble for our introduction to the concept of transdisciplinarity. Noble has had reason to think extensively about the relationship of her own practice to the world of science, having received a US National Science Foundation Arts and Writers Award in 2008, resulting in her Antarctica photo series, and through her work on bees in collaboration with apiculturist and physicist JeanPierre Martin. For Noble 'Like science, art experiments and measures-although measurement for art has another meaning altogether-more to do with the tenor of feeling, with the sensibility of the psyche, and the formation of cultural consciousness'. Kate Brettkelly-Chalmers, 'A Conversation with Anne Noble,' Ocula, February 13, 2015, https://ocula.com/magazine/conversations/anne-noble/. However, our interpretations in this paper shouldn't be considered as representative of Noble's thoughts, but as our own take on transdisciplinarity. 
self-reflexivity. ${ }^{3}$ By beginning with a macro-view of health, there is potential for public health to lose sight of the individual and particular impacts of its ambitions. Further, there is a hallmark impulse to fix, find solutions, and to resist open-endedness and uncertainty. Preoccupation with science-based forms of evidence may hamper the ability of those who work in public health to think in an open and creative manner. By contrast, artists often (though not always) tend to approach the questions that drive their work in an explorative, open-ended way. Artists, engaging with fundamental questions of society, yet with the freedom to take a step sideways, address many of the same thematic issues that public health is grappling with. We suggest that a thoroughgoing transdisciplinary engagement between art and public health may enrich the discipline of public health and provide novel opportunities for artists.

The challenge of climate change is complex, and despite overwhelming scientific evidence showing its genesis, causes, effects, and threats, action to combat climate change at both global and national levels remains vague and under-committed. It is clear that convincing scientific evidence alone falls short of galvanising the widespread economic and cultural change that

3 Self-reflexivity is a term that carries a number of nuanced definitions. For the purposes of this article, we are using self-reflexivity as it relates to transdisciplinarity - as an approach that 'systematically scrutinises in which ways knowledge is produced and used by different societal actors in support of their concerns', and 'methodically challenges how science itself deals with the tension between its constitutive pursuit of truth and the ever increasing societal demand for the usefulness of its results'. Thomas Jahn, Matthias Bergmann, and Florian Keil, 'Transdisciplinarity: Between Mainstreaming and Marginalization,' Ecological Economics 79 (2012): 1-10. Similarly, we understand self-reflexivity as an approach that "encourage[s] processes of critical assessment and social learning on the background values and assumptions guiding research, and on the socioinstitutional structures supporting particular norms and practices'. Florin Popa, Matthieu Guillermin, and Tom Dedeurwaerdere, 'A Pragmatist Approach to Transdisciplinarity in Sustainability Research: From Complex Systems Theory to Reflexive Science,' Futures 65 (2015): 45-56. 
is needed to address climate change. ${ }^{4}$ On the one hand, better communication of scientific evidence is required to enable policymakers and communities to fully understand the nature of the issue; the arts are one vehicle through which to achieve this. On the other hand, complex problems require novel methods and ways of thinking. Transdisciplinary engagement encourages a revision of assumptions, and prompts new ways of seeing and thinking. The public health and art interface is one possible site of collaborative endeavour. It is compelling because while there is substantive thematic overlap between art and public health, there are near-polarised preoccupations with types of knowledge and affect.

We begin this paper with a brief overview of disciplinarity and transdisciplinarity. Complex problems like climate change are one area where a disciplinary approach might compromise our ability to enact radical new ways of thinking. The concept of wicked problems has been developed to describe these kinds of complex issues. We discuss the concept of wicked problems and consider how transdisciplinarity might be a way of responding to these problems. We then turn to look at the discipline of public health, interrogating its radical potential and identifying ways in which it currently falls short of this potential. Having introduced these concepts, we discuss how art and public health might meet in a transdisciplinary manner, offering some examples of artists who are already working in a way that moves towards transdisciplinarity. We finish with a caution to avoid the instrumentalisation of art in this context.

4 Andreas Kläy, Anne Zimmerman, and Flurina Schneider, 'Rethinking Science for Sustainable Development: Reflexive Interaction for a Paradigm Transformation,' Futures 65 (2015): 72-85. 


\section{Disciplinarity (r)evolution}

Disciplinarity is situated in an ontological and epistemological commitment to specialisation and the acceptance of objective truth, something most effectively pursued through the accumulation of knowledge and methodologies that support specialisation. ${ }^{5}$ However, this epistemic circularity is overly committed to boundaries and is closed off from the relative 'truths' of other modes of knowing and knowledge-making. ${ }^{6}$ A gesture towards multidisciplinarity or interdisciplinarity may enrich knowledge production; however, as leading transdisciplinary thinker Basarab Nicolescu points out, these attempts to work across disciplines typically remain committed to the 'service of the home discipline'. A total dissolution of the boundaries between disciplines, on the other hand, is, for Nicolescu, an unnecessarily anarchic abandonment of methodology. Instead, Nicolescu forwards an argument for transdisciplinarity, a pursuit which is at once between, across, and beyond disciplinarity.

Transdisciplinarity differs from multidisciplinarity and interdisciplinarity in that it seeks knowledge beyond disciplines-new knowledge and ways of knowing - that would likely be obscured by remaining within the scope of disciplinarity. In contrast, multidisciplinarity refers to 'studying a research topic in not just one discipline but in several simultaneously'. ${ }^{8}$ An example of this would be a research programme in which researchers from different disciplines collaborate to produce a

$5 \quad$ Patricia Leavy, Essentials of Transdisciplinary Research: Using Problem-Centred Methodologies (London and New York: Routledge, 2011).

6 Peter Osborne, 'Problematizing Disciplinarity, Transdisciplinary Problematics,' Theory, Culture \& Society 32, no. 5-6 (2015): 3-35.

7 Basarab Nicolescu, 'Methodology of Transdisciplinarity: Levels of Reality, Logic of the Included Middle, and Complexity,' Transdisciplinary Journal of Engineering \& Science 1, no. 1 (2010): 22.

8 Ibid. 
body of knowledge on a shared topic from each of their particular disciplinary perspectives. Interdisciplinarity refers to 'the transfer of methods from one discipline to another' ${ }^{9}$ In this regard, interdisciplinarity can produce new types of knowledge, but still remains committed to the 'home' discipline from which it is operationalised. Transdisciplinary work, on the other hand, refers to a process of knowledge production that is attendant to the diverse realms of sciences, technology, society, and spirituality. The knowledge of each dimension is treated as equal, and transdisciplinary engagement is practiced throughout the entire process.

Hybridity between universal ideas and particular experience, or the macro and micro, is a central feature of transdisciplinarity. Further, as Julia Thompson Klein notes, transdisciplinarity has affinities with earlier discourses including transcendence, problem solving, and transgression. ${ }^{10}$ Transdisciplinary research has been discussed and used across many disciplines and research fields, most notably in the social sciences, ${ }^{11}$ ecological studies, ${ }^{12}$ health, ${ }^{13}$ and public health. ${ }^{14}$ Public health efforts to work in a transdisciplinary manner have often included either integrating with social science approaches and methodolo-

9 Ibid.

10 Julia Thompson Klein, 'Reprint of "Discourses of Transdisciplinarity: Looking Back to the Future," Futures 65 (2015): 10-16.

11 Encarnacion Gutierrez Rodríguez, Manuela Boatc $\square$, and Sérgio Costa eds., Decolonizing European Sociology: Transdisciplinary Approaches (London and New York: Routledge, 2016).

12 Örjan Bodin et al., 'Theorizing Benefits and Constraints in Collaborative Environmental Governance: A Transdisciplinary Social-Ecological Network Approach for Empirical Investigations,' Ecology \& Society 21, no. 1 (2016): 40.

13 Patricia Rosenfield, 'The Potential of Transdisciplinary Research for Sustaining and Extending Linkages Between the Health and Social Sciences,' Social Science \& Medicine 35, no. 11 (1992): 1343-1357.

14 Debra Haire-Joshu and Timothy D. McBride eds., Transdisciplinary Public Health: Research, Methods, and Practice (San Francisco: Josey-Bass Publishers, 2013); 'Harvard Transdisciplinary Research in Energetics and Cancer Center,' Harvard T.H. Chan, https://www.hsph.harvard.edu/trec/ 
gies to enrich the narratives and understandings around issues, ${ }^{15}$ or collaborating with non-governmental organisations and communities to co-create research and change in line with efforts to do research with rather than to subjects. ${ }^{16}$ Here, we build on this existing of public health to engage in a transdisciplinary manner by suggesting that the public health-art interface is a new site for such engagement. ${ }^{17}$

The value of transdisciplinary work as a praxis that reaches across knowledges is well-recognised in research on sustainability. For instance, Florian Popa, Matthieu Guillermin, and Tom Dedeurwaerdere argue that 'solving sustainability problems involves decisions on values that require civic participation and the building of social legitimacy for proposed transition pathways', something that conventional scientific methodologies do not adequately provide. ${ }^{18}$ To build social legitimacy, both process and relationships are identified as central components of transdisciplinary approaches, with each stage of research being a co-created effort, and new knowledge being created and shared throughout a project. ${ }^{19}$ Crucially, sustainability in the context of climate change is identified as a field of research that is overly complex for conventional approaches; it requires new, more embedded approaches to research that pay closer attention to the aligning values of different disciplines. Turning now to look at

15 For example, see Chandra Ford and Collins Airhihenbuwa, 'Critical Race Theory, Race Equity, and Public Health: Toward Antiracism Praxis,' American Journal of Public Health 100, supp. 1 (2010).

16 For example, see Edward Lawlor et al., 'Methodological Innovations in Public Health Education: Transdisciplinary Problem Solving,' American Journal of Public Health 105 (2010).

17 For example, see Maritt Kirst et al., eds., Converging Disciplines: A Transdisciplinary Research Approach to Urban Health Problems (New York: Springer, 2011).

18 Popa et al., 'A Pragmatist Approach,' 45.

19 David Simon and Friedrich Schiemer, 'Crossing Boundaries: Complex Systems, Transdisciplinarity, and Applied Impact Agendas,' Current Opinion in Environmental Sustainability 12, no. 6 (2015): 6-11. 
the concept of 'wicked problems', we consider what it is about these issues that compels novel approaches.

\section{Defining wicked problems}

The concept of 'wicked problems' provides a useful prism through which to conceptualise the problem of climate change in a clear light-as an urgent issue we all indisputably face, but one which is paradoxically characterised by inertia on a global scale. The term was coined in the early 1970s by urban planners Horst Rittel and Melvin Webber, who observed that traditional rational-analytical planning models were failing to provide useful solutions for certain types of complex social problems. ${ }^{20} \mathrm{~A}$ distinction was drawn between problems which were 'wicked' (complex and very resistant to resolution) or 'tame' (generally resolvable through straightforward planning or policy processes). The term has subsequently come to be more broadly applied to complex social policy problems, but also, recently, to climate change. In this context, 'wickedness' refers not to notions of evil, but rather to fiendish complexity and apparent intractability. ${ }^{21}$ At the crux of this apparent insolubility lies a lack of consensus about the nature of the problem itself and how best it might be addressed. ${ }^{22}$ As Martin Carcasson writes:

20 Horst Rittel and Melvin Webber, 'Dilemmas in a General Theory of Planning,' Policy Sciences 4, no. 2 (1973): 155-69.

21 Louise Signal et al., 'Tackling "Wicked" Health Promotion Problems: A New Zealand Case Study,' Health Promotion International 28, no. 1 (2012): 84-94.

22 This is not to suggest that the nature of anthropogenic climate change itself is contested, but we do make two observations: first, that the sway of denialism does affect global action on climate change (for example, the United States pulling out of the Paris Accord); second, the nature of the problem of anthropogenic climate change is contested in terms of contemporary and historical responsibility, scale of responsibility (i.e. individual responsibility versus corporate versus governmental responsibility), and in terms of the particular social and economic causes of intractability (i.e. can capitalism and a climate-friendly future coexist?). 
'Wicked problems have no technical solutions, primarily because they involve competing underlying values and paradoxes that require either tough choices between opposing goods or innovative ideas that can transcend the inherent tensions'. ${ }^{23}$

In addition to climate change, other examples of wicked policy problems include social inequality, obesity, terrorism, and the loss of biodiversity. The characteristics of wicked problems include: a lack of consensus in problem definition and in what is considered 'valid' evidence; complex and interdependent causality (which tends to shift over time); a lack of clearly optimal solutions; and a requirement that set views and behaviours be changed en masse in order to address the cause. ${ }^{24}$

These characteristics tend to confound traditional approaches to policy making and hamper the development and implementation of clear and practical directives along classical rational-analytical lines. In turn, chronic policy failure contributes to a sense of political and public apathy about the apparent intractability of these problems. Wicked problems are therefore a political 'hot potato' as they confound the impulse to bring order through the linear development of clear policy directives. There is no easy fix or rational formula for wicked problems. As such, a common tendency of governments is to either avoid addressing such problems altogether or to oversimplify the inherent complexity when proposing solutions, something which may actually compound the very wickedness of the problem.

23 Martin Carcasson, 'Tackling Wicked Problems Through Deliberative Engagement,' National Civic Review 105, no. 1 (2016): 44-47.

24 Dominic Duckett et al., 'Tackling Wicked Environmental Problems: The Discourse and its Influence on Praxis in Scotland,' Landscape \& Urban Planning 144 (2016): 44-56; 'Tackling Wicked Problems: A Public Policy Perspective, Australian Government,' Australian Public Service Commission, http://www.apsc.gov.au/publications-and-media/archived-publications/publications-archive/tackling-wickedproblems; Domenico Dentoni and Verena Bitzer, 'The Role(s) of Universities in Dealing with Global Wicked Problems Through Multi-stakeholder Initiatives,' Journal of Cleaner Production 106 (2015): 68-78. 
This 'existential paralysis' poses a critical challenge to addressing issues such as climate change, but arguably also represents the very terrain which ought to be probed for novel ways of thinking that transcend traditional responses. Art has always concerned itself with the existential conundrums of human existence. Might art help us to map the complexity of climate change, and to crystallise the urgently required call to arms which has so far eluded both climate science and governments?

Tackling wicked problems has been conceptualised as a task requiring a willingness to step outside of the familiar: a process requiring a willingness to see and acknowledge the macro-picture, and to imagine and innovate solutions beyond traditional unidisciplinary approaches in recognition of the fact that multiple sectors contribute to and are impacted by these problems, and therefore multiple sectors ought to have a hand in developing the means to address them. ${ }^{25}$ Inevitably, this requires a willingness to recognise and live with a divergence in values in the navigation of collaborative solutions and to assent to the 'trade-offs' this may require. ${ }^{26}$

Three main strategies have been proposed to tackle wicked problems: authoritative/technocratic strategies, whereby the responsibility for problem solving is handed over to an 'anointed few' and solutions are drawn from a narrow and familiar toolbox; competitive strategies, whereby innovation is generated through competition between stakeholders; and collaborative strategies, whereby influence over problem-solving is dispersed among many and varied stakeholders, an approach grounded in the view that transdisciplinarity, a partnership model, and diverse stakeholder engagement engenders innovation. ${ }^{27}$ The current lit-

25 Dentoni and Bitzer, 'The Role(s) of Universities.'

26 Brian Head, 'Wicked Problems in Public Policy,' Public Policy 3, no. 2 (2008): 101-118.

27 Australian Public Service Commission, 'Tackling Wicked Problems.' 
erature around wicked problems strongly indicates that the collaborative approach is the most effective. This is partly because the mind-set and behaviour change required in tackling wicked problems is understood to be best achieved when stakeholders manage to establish a shared commitment to a win-win view of problem solving. ${ }^{28}$

These insights around the importance of cross-sector collaboration have engendered a proliferation of 'multi-stakeholder initiatives' (MSIs), particularly in the areas of agriculture and food production, ${ }^{29}$ the addressing of complex social issues, ${ }^{30}$ and health promotion. ${ }^{31}$ These are governance arrangements in which a range of stakeholders-chiefly from business and civil society, but sometimes also from government and academiacome together in an 'institutionalised platform for collaboration' to share knowledge and resources in the development of mutually acceptable solutions. ${ }^{32}$ There is evidence that the 'collective learning' that arises from these arrangements is beneficial for the stakeholders involved. However, the utility of this novel model of problem-solving also suggests an untapped potential for a broader, transdisciplinary approach to addressing the 'super-wicked' problem of climate change. ${ }^{33}$ As Domenico Dentoni and Verena

28 Ibid.; Edward Webster and Anne Khademian, 'Wicked Problems, Knowledge Challenges, and Collaborative Capacity Builders in Network Settings,' Public Administration Review 68, no. 2 (2008): 334-9; Ans Kolk, Rob van Tulder, and Esther Kostwinder, 'Business and Partnerships for Development,' European Management Journal 26 (2008): 262-273.

29 Karin Bäckstrand, 'Multi-stakeholder Partnerships for Sustainable Development: Rethinking Legitimacy, Accountability, and Effectiveness,' Environmental Policy \& Governance 16, no. 5 (2006): 290-306.

30 John Selsky and Barbara Parker, 'Cross-sector Partnerships to Address Social Issues: Challenges to Theory and Practice,' Journal of Management 31, (2005): 849-873.

31 Signal et al., 'Tackling "Wicked" Health Promotion Problems.'

32 Dentoni and Bitzer, 'The Role(s) of Universities.'

33 Richard Lazarus, 'Super Wicked Problems and Climate Change: Restraining the Present to Liberate the Future,' Cornell Law Review 94, no. 5 (2009): 1153-1234. 
Bitzer note, a key benefit of MSIs is the fact that this model of decision-making has the potential to "counteract the scientific uncertainty of wicked problems by involving actors that cut across different societal sectors and multiple knowledge domains' and to 'bring together actors with complementary resources to address issues that actors would not be able to individually'. ${ }^{34}$ It is not too great a conceptual stretch to consider the extent to which art, arguably the conceptual opposite to science, might be operationalised as an imaginative resource in the expansion of such MSIs. At very least, it may help broker universal and robust agreement on what, precisely, we are all facing.

\section{Public health: Radical potential, totalising tendencies}

While the discipline of public health is rooted in an implicit commitment to social and environmental justice, and therefore naturally challenges status quo approaches that work against these values, there is also a risk that the macro view of public health compromises its ability to understand the particular. That is, the tendency of public health to look to population-wide, generalisable solutions can limit the ability to be openly self-reflexive, and to remain cognisant of the unintended ramifications of its ambitions. For example, an ethical critique of population-based interventions (such as vaccination, or prenatal screening for conditions such as Down Syndrome $)^{35}$ is that individual beliefs and rights are marginalised by a conception of 'public good' that is essentially nonconsultative and exclusively values scientific ways of knowing.

34 Dentoni and Bitzer, 'The Role(s) of Universities,' 70.

35 Sarah Donovan, 'Compelling choices: Tensions in the practice and experience of prenatal screening in New Zealand,' (Ph. D., Victoria University of Wellington, New Zealand, 2010). 
Public health is an implicitly values-driven discipline. A core concern with social justice and maximising equity is played out in actions and policies that aim to have a beneficial impact at a population-wide level; as Kevin Dew suggests, it is a 'thoroughly social and political enterprise'. ${ }^{36}$ Public health's imaginings are implicitly concerned with how society should or could be. In this respect, it shares art's (often) commentative impulse and its preoccupation with imagining other possible futures. Dew notes that a commitment to advocacy and social change is a distinguishing feature of public health as an academic discipline. With this, he notes, there is latent radical potential: 'From this perspective, public health is not conservative; it is not preserving the status quo. It is transformational and utopian in vision. Public health advocates may, for example, envisage a society where there is no inequality in health outcomes'. ${ }^{37}$

In line with social change and evolving health challenges, the foundational moral values of public health have also shifted over time. As ongoing struggles with old foes such as infectious diseases and the emergence of new health threats such as antibiotic resistance and widespread obesity shows us, public health seldom wins its battles definitively. This is also a lesson of climate change, which threatens to disrupt many established social and environmental determinants of health. ${ }^{38}$ As such, for Lisa Lee and Christina Zarowski, having an appreciation of the history of public health is an essential element in understanding how the contemporary relationship between citizens, sci-

36 Kevin Dew, 'Introduction: Public Health Theories and Theorizing Public Health,' in The Cult and Science of Public Health: A Sociological Investigation, ed. Kevin Dew (New York: Berghahn Books, 2012), 1-10.

37 Ibid., 2.

38 For more on climate change and health impacts, see 'Climate Change,' World Health Organization, http://www.who.int/globalchange/en/; and 'Climate Change and Health: Fact Sheet,' World Health Organization, http://www.who.int/ mediacentre/factsheets/fs266/en/. 
ence, and the state have come about, and how these continue to be negotiated and contested. ${ }^{39}$ Similarly, art is a powerful and under-utilised 'record-keeping tool' and a resource for radically reimagining other possible worlds: 'Art can show us where we have been, where we are now, and where we might go. Art can be a catalyst for change ... [it can] lead us towards a creative, just, and sustainable future'. ${ }^{40}$

As Dew notes, where 'old' public health was oriented firstly towards sanitation and infectious disease before shifting its focus to the control of risk factors for diseases of 'lifestyle', contemporary public health now has a strong focus on social determinants of health and illness as the broader 'causes of the causes'. ${ }^{41}$ It is now widely understood that social and socioeconomic factors are potent determinants of health. These interlinked macro-factors are most meaningfully addressed through public policy and government-led or coordinated cross sector efforts in which connections are drawn between interlinked yet disparate social conditions.

While the 'older' public health problems such as sanitation may be readily addressed with technical solutions, health problems resulting from social and socio-economic inequalities are not so easily assuaged. Instead, they necessitate a 'transformation in the way society itself is organized', including such varied (but complexly interlinked) measures as higher wages, increased production of food, and reform of taxation. ${ }^{42}$ This is a radical vision of change motivated by rights-based notions such

39 Lisa Lee and Christina Zarowski, 'Foundational Values for Public Health,' Public Health Reviews 36, no. 2 (2015).

40 From https://www.artclimatechange.org/.

41 This term was coined by Geoffrey Rose. See Geoffrey Rose, Strategy of Preventive Medicine (Oxford: Oxford University Press, 1992).

42 Kevin Dew, 'Preface: Public Health as Social Activism: A Slightly Abashed Hagiography,' in Critical Perspectives in Public Health, eds. Judith Green and Ronald Labonte (Abingdon and New York: Routledge 2008), 1-11. 
as social justice and social security. As health and social issues continue to evolve, then, public health practitioners must reflect on what the purpose of public health is and what its guiding moral foundations are. Such reflection enables us to remain grounded while we address wicked problems that require flexible, highlevel, and imaginative thinking.

\section{How can art and public health work together?}

By making our assumptions about the goals of public health more visible and questionable, transdisciplinary engagement can open us up to new ways of working. For example, in its capacity to personalise and articulate complex social issues and processes, art can help provoke self-reflexivity about our own practices and worldviews. It can provoke reflection on the hidden relationships between individual lives and the bigger picture (including economic processes, capital, social position, power, ethnicity, gender, life chances, and good health). Art has the power to both see differently and to speak to people in different ways, ways which may have more resonance than conventional modes of scientific output and communication. As Australian visual artist and academic John Read notes, artists are 'familiar with the importance of wonder, aware of the power of intuition, and skilled in the aesthetic visualisation of ideas and feelings', and thus have much to contribute to and gain from transdisciplinary ways of working. ${ }^{43}$ To provoke an emotional response (and potentially, an action) public health's envisioning of these problems must gain popular and emotive currency. For instance, a statistic on homelessness

43 Quoted in Valerie Brown, John Harris, and Jacqueline Russell eds., Tackling Wicked Problems Through the Transdisciplinary Imagination (London: Earthscan, 2010), p. xx 
or the current rate of household poverty tells part of the story, but it does not necessarily resonate in a manner that builds public interest and meaningful institutional action.

Regarding climate change, many artists both locally and internationally are already working in innovative and discipline-bending ways to evoke action. Three intriguing examples are Amy Howden-Chapman, Amy Balkin, and Huhana Smith. Howden-Chapman is a New Zealand artist living and working internationally. Her collaboration with Auckland curator Abby Cunnane, The Distance Plan, adopts a multidisciplinary approach to establish a lexicon with which to provoke action on climate change. ${ }^{44}$ Balkin, an American artist, has engaged with market-based emissions mitigation strategies to undermine the processes of pollution using the tools that can serve their interests. ${ }^{45}$ Finally, Smith (Ngāti Tukorehe/ Ngāti Raukawa ki te Tonga) has articulated that art may be an effective bridge between mātauranga Māori and scientific knowledge. ${ }^{46}$

Howden-Chapman and Cunnane worked together on The Distance Plan \#4-Climate Change and Art: A Lexicon. Drawing on contributors from a range of backgrounds including public health, economics, political science, and art history, this publication sought to catalogue and develop a shared lexicon by which action on climate change might be pursued. For HowdenChapman and Cunnane, 'The Distance Plan positions the arts as having a central role in responding to [climate change]'. ${ }^{47}$ Rather than attending to the issue of climate change in terms of science or culture only, the lexicon draws them together to

44 Amy Howden-Chapman and Abby Cunnane, 'Evolving Vocabulary,' The Distance Plan\#4, 2016, http://thedistanceplan.org/pdf/DP_Issue4.pdf.

45 'Public Smog,' http://www.publicsmog.org/.

46 See 'Climate change and coastal Māori communities,' National Science Challenges http://www.deepsouthchallenge.co.nz/projects/climate-change-coastal-maoricommunities; 'Manaaki Taha Moana,' https://www.mtm.ac.nz/mtm/.

47 Howden-Chapman and Cunnane, 'Evolving Vocabulary,' 7. 
interrogate the ways language changes and affects both thought and action. By presenting a number of terms-for example, the fuck lycra conundrum, living borders, tragic triumph, elongated governance, social tipping points-and embedding them with definitions, imagery, and context, the lexicon is a starting point for thinking across conceptual frames and methodologies. The lexicon is about developing new ways of thinking and acting, in recognition that existing frameworks must evolve if we are to address climate change.

As well as drawing on people with expertise from different disciplines, artists can draw on the strategies and functions of different disciplines and spheres. Balkin, for example, has adopted the functions of capitalist market-based and legal approaches to mitigating emissions in a way that draws attention to how these approaches can be mobilised to different ends. Her project, Public Smog, does this in two ways. First, Balkin purchases carbon offsets to create a 'public park' of clean air in the atmosphere. Through purchasing them in the public interest, and therefore making those offsets unavailable to polluters, she subverts the processes of market-based emissions mitigation strategies. This process also calls attention to the ways that we value clean air. Second, Balkin has attempted to have the earth's atmosphere legally recognised as a UNESCO World Heritage Site. UNESCO World Heritage Sites must be 'of outstanding universal value'; they must 'contain the most important and significant natural habitats for in-situ conservation of biological diversity, including those containing threatened species of outstanding universal value from the point of view of science or conservation'. ${ }^{48}$ Balkin approached all UNESCO member states, only receiving a positive response from the Kingdom of Tonga. This attempt reframes 
the atmosphere in terms of its interconnected and vital value rather than reducing the atmosphere to a site of commodification and resource.

Smith is Head of the School of Art at Massey University and is a practicing artist. Her collaborative research work, Manaaki Taha Moana (MTM), drew together mātauranga Māori with scientific knowledge to effect novel and locally relevant action on coastal ecosystems. ${ }^{49}$ As she notes, 'We are utilising Western Science and mātauranga Māori knowledge, as well as participatory modelling tools and processes, to assist iwi/hapu to evaluate and define preferred options for enhancing/restoring coastal ecosystems'. ${ }^{50}$ Smith is attempting to establish new ways of knowing that account for conventionally distinct and even oppositional ontological and epistemological foundations. To do so, this work places emphasis on the process of forming, doing, and articulating research as a wholly collaborative approach that draws on the existing knowledge and interests of all parties involved. In the context of Aotearoa New Zealand, and with the communities that Smith's work involves, this approach responds to the complex ways that climate change affects us now and will affect us in the future. More recently, Smith has worked with local Māori on the National Science Challenge's Vision Mātauranga Deep South Project ${ }^{51}$ to use their 'whakapapa and korero tuku iho [ancestral knowledge] to encourage a better community understanding of climate change and develop adaptation strategies in artistic and design formats'. ${ }^{52}$

Smith's role in the Deep South Project's 'Adaptation Strategies to Address Climate Change Impacts on Coastal Māori

49 See 'Manaaki Taha Moana.'

50 Ibid.

51 National Science Challenges, 'Climate Change and Coastal Māori Communities.'

52 Yvonne O'Hara, 'Māori Knowledge Brought to Bear on Problem,' Otago Daily Times, Jan 20, 2018, https://www.odt.co.nz/news/national/maori-knowledge -brought-bear-problem. 
Communities' is particularly illustrative of the novel potential of transdisciplinary-type work. For this project, based around communities in the Horowhenua-Kāpiti rohe, art and design acted as a bridge between mātauranga Māori, local knowledge, and scientific knowledge. Rather than being subservient to any of these, the art and design processes were essential co-producers of context-specific knowledge and understanding. For those involved in the project: "the power of art or design lies also in their capacity to crack open binaries (science/indigenous knowledge, process/content, etc.), generating new ways of thinking, challenging assumptions, and devising solution'. ${ }^{53}$ This capacity indicates that, when integrated into such a project, art can evoke transdisciplinary engagement. This example also demonstrates the impact of transdisciplinary-type work in effecting meaningful action. As Martin Bryant, Penny Allan, and Smith explain, the challenge for this project lay in gaining understanding of the scale and immediacy of the problem, getting local buy-in to planning strategies for action, and in empowering the local community to diagnose and respond to the threat of sea-level rise. In meeting these particular social and cultural challenges, this project enabled meaningful action.

The three examples provided here each exhibit a distinctive approach that reflects an underlying dissatisfaction with the status quo. As Howden-Chapman and Cunnane point out in The Distance Plan, Margaret Atwood argues that 'everything change is perhaps a more appropriate term than climate change ${ }^{54}$ In the public health space, the New Zealand Centre for Sustainable Cities programme, Resilient Urban Futures, in its commitment to 'systems thinking', was a good example of a research programme

53 Martin Bryant, Penny Allan, and Huhana Smith, 'Climate Change Adaptations for Coastal Farms: Bridging Science and Mātauranga Māori with Art and Design,' The Plan Journal (forthcoming).

54 Howden-Chapman and Cunnane, 'Evolving Vocabulary,' 7. 
that thought across disciplines. ${ }^{55}$ However, this programme remained committed to privileging scientific ways of knowing; there is room for a deeper and more open engagement that relinquishes the certainty of discipline-situated knowledge. The more totalising tendencies of public health, as a fundamentally population- and science-based discipline, can creep into pursuits that are oriented towards social justice. This creep holds public health within a paradigm that attaches itself to the pursuit of knowing and finding generalisable knowledge that could flatten or devalue individual experience.

The arts, on the other hand, are a natural setting for experimentation with the possibilities of the unknown and with visions of radical change. This is a fundamentally different way of working than public health, with a greater commitment to explorative, suggestive, and emotive work that doesn't insist on answering every question. Yet many artists and art practices seek to affect people, provoke thought, and catalyse change. For example, 'social practice' is an art practice that utilises and develops participatory community engagement, often with the motivation to affect community-led change. This type of motivation has appeared in many guises, one being 'social sculpture', a concept coined in the 1970s that describes the intention of manifesting the potential of art to affect society. ${ }^{56}$ For instance, the Social Sculpture Research Unit is a UK-based organisation that 'explores transdisciplinary creativity and vision towards the shaping of a humane and ecologically viable society'. ${ }^{57}$ In New Zealand, The Arts Foundation recently published a piece looking at the place of the arts in society. They identified the tendency of

55 'Resilient Urban Futures,' New Zealand Centre for Sustainable Cities, http://sustainablecities.org.nz/resilient-urban-futures/

56 See http://www.tate.org.uk/art/art-terms/s/social-sculpture

57 'Social Sculpture Research Unit,' Social-sculpture, http://www.social-sculpture. org/ 
New Zealand culture to devalue the arts (to view them as 'nice to have' rather than as a fundamental and necessary expression of human creativity), but argued that the arts have a central role to play in fuelling innovation and discovery within the context of enormous global challenges:

It's not just our responsibility to shape the world we live in for now, we also need to ensure that the world is a place where future generations want to live. The arts have a powerful role to play in the development of multiple endeavours and we must make sure it is not siloed by language or expectations. We all have a responsibility to invest in the arts as a major contributor to innovation, education, communities, individual wellbeing, and tackling the great problems of our time. ${ }^{58}$

The arts and sciences have a long symbiotic history, with artists like Leonardo da Vinci being particularly well-known for his scientific contributions, and the documentary Particle Fever making connections between the imaginative processes and pursuits of both art and science. ${ }^{59}$ Less well-known examples include the invention of the stethoscope by artist and musician Rene Leannec, camouflage by painter Abbott Thayer, the first pill-making machine by artist William Brockedon, and the development of modern pixelation through the work of painter Georges Seurat. ${ }^{60}$ Beyond these more technical advances, for a discipline like public health, the ability of the arts to compel emotive responses

58 'Exceptional is the New Normal,' The Arts Foundation, October 25, 2017, http:// www.thearts.co.nz/news/exceptional-is-the-new-normal.

59 Helen Thompson, 'Art and science collide in the discovery of the Higgs Boson,' Smithsonian, March 31, 2014, https://www.smithsonianmag.com/science-nature/ art-and-science-collide-in-the-discovery-of-the-higgs-boson-180950253/.

60 Robert Root-Bernstein, 'Symbiotic art and science: Can artists make scientific discoveries?' Art Works Blog, March 15, 2011, https://www.arts.gov/art-works/2011/ symbiotic-art-science-can-artists-make-scientific-discoveries 
and to distil complexity is particularly valuable to effecting cultural change. Artists have been immensely active amongst antiwar movements for example, contributing to a culture of discontent through the creation of symbols and aesthetic languages to mobilise around. ${ }^{61}$ Artists also regularly work in a more practical sense with public health, playing a pivotal role in public outreach through the design of public campaigns. ${ }^{62}$

However, in Aotearoa New Zealand the relationship between the arts and public health remains unsure of its footing. Public health scientists, so committed to the primacy of logic and rationality, often struggle to consider the arts beyond their usevalue as a tool of communication. The arts are a natural place to look to when a complex problem requires distillation into something that provokes a novel emotional response. For this reason, the 'hard' disciplines have often looked to the arts simply as a tool of communication (a fact which becomes obvious when the terms 'art' and public health' are combined in a search for literature on this relationship). In this way, art is subordinated and placed into the service of science. A transdisciplinary approach, on the other hand, requires that disciplines meet in a non-hierarchical manner. The following section looks at the processes of transdisciplinary work, and how these might undermine some of the hidden totalising tendencies of disciplinarity.

61 For example, the Art Workers Coalition, 'And Babies' is a germinal example of 'art propaganda', printed as a contribution to anti-Vietnam War protests in the United States, and displayed as part of a performative protest in front of Picasso's 'Guernica' at the Museum of Modern Art New York in 1969. Guernica itself is illustrative of the place of the arts in commenting on war, depicting the bombing of the Basque town of Guernica by Nazi and Italian Fascists in 1937.

62 For example, New Zealand's Health Promotion Agency is a bridging agency between public health issues and public campaigns that employ artists and designers to attempt to reach the public and effect change on issues such as smoking and alcohol. 


\section{Beyond instrumentality}

The instrumentalisation of art by scientists and public health practitioners diminishes art to a use-value and orientates it strictly towards outcomes. By both beginning and stopping at a point where public health sees art as a way only to communicate, to better understand, and to provoke a (pre-determined) response, we cannot go beyond a cross-disciplinary approach that instrumentalises art in the service of the home discipline. The Wellcome Institute in the UK, an institution that explores health through connecting science, medicine, life, and art, has grappled with the competing demands of open-ended art practice and the justification of expenditure through use-value and outcomes. Pre-eminent curator, Ken Arnold, observes that, in an institution eager to spend its money efficiently, concerns with what is produced and the effects they have must always be carefully scrutinised and considered'. ${ }^{63}$ For a discipline that is rooted in the pursuit of proof and evidence, and often tied to the demands of funders who require outcomes reports, letting go of the pursuit of certainty, and opening projects not only to the methods, but also the less specific or differing aims of other disciplines, can be challenging. However, as Arnold notes, these types of open-spirited collaborations can have enormously rich effects for the people involved and can result in novel and unexpected projects.

The experience of the Wellcome Institute is illustrative of the unexpected ways that transdisciplinary work can manifest. Arnold observes that, positioned between scientists and artists, the curator plays a crucial role in navigating the conceptual connections between disciplines. Describing curating as

63 Ken Arnold, 'A Very Public Affair: Art Meets Science,' Interdisciplinary Science Reviews 42, no. 4 (2017): 331-334. 
an art form in its own right, Arnold notes that the curator must construct an exhibition through exploration of the components that truly connect, rather than forcing pieces together to fit a narrative or outcome that has been pre-determined. As a result, some of the Wellcome exhibitions have re-adjusted their focus to illuminating the processes of medical research, rather than simply portraying research findings. Crucial to these observations is that the experiences of the Wellcome Institute are the result of explorative processes of working that have had to navigate the uncertainties of transdisciplinary engagement. There are undoubtedly other lessons to be drawn from the Wellcome Intitute's extensive experience in this area, but the one we wish to emphasise is that any transdisciplinary engagement must forge its own path and be wholly open to uncertainty. The underlying question of transdisciplinary work must therefore be: what can be created that is new?

Ultimately, then, the transdisciplinary process is as important as the outcomes it produces. Recognising this requires a rethinking of how art is valued in research. Further, quantifying or demonstrating the value of process when trying to attain conventional funding is challenging. However, it should be noted that many funders are increasingly emphasising community and stakeholder engagement as fundamental aspects of research; the ways in which these types of engagement are measured and discussed may assist with shifting a greater focus towards valuing process, without pre-determination of outcomes. ${ }^{64}$

Kaupapa Māori research places a high value on process. Further, it is exemplary of the potential for transdisciplinary engagement and of the potential for research that crosses

64 Of course, some funders are also insisting that outcomes are determined in the form of aims, Key Performance Indicators (KPIs), or milestones, which are used to report against. Despite being outcome-oriented, these can also contribute to valuing process, in that an outcome or KPI might in itself be engagement. 
paradigms and worldviews. It also creates a shared ownership of research by all stakeholders. In a Western worldview that privileges scientific method, the arts are often accorded less value than other disciplines. As noted earlier, the oft-touted justification for the arts within this paradigm is its communication value; this justification privileges the scientific paradigm. In te ao Māori, however, the arts are often understood to be a fundamental and living expression of culture, tipuna, whakapapa, and spirituality, and are accorded an interconnected value that doesn't attempt to pit the arts against other pursuits.

In her germinal text, Decolonizing Methodologies, Linda Tuhiwai Smith argues that the very notion of disciplinarity is a colonising worldview:

Most of the traditional 'disciplines' are grounded in cultural world views which are either antagonistic to other belief systems or have no methodology for dealing with other knowledge systems. Underpinning all of what is taught at universities is the belief in the concept of science as the all-embracing method for gaining an understanding of the world. ${ }^{65}$

Enclosed disciplinarity is not only closed to other knowledge systems, but is also, in many instances, bound-up with colonial enterprises. Though public health has a strong inclination towards social justice, community partnerships, and te ao Māori, ${ }^{66}$ the discipline also shares histories with totalising, racist, and sexist practices. ${ }^{67}$ While many of these practices

65 Linda Tuhiwai Smith, Decolonizing Methodologies: Research and Indigenous Peoples, 2nd edition (London and New York: Zed Books), 68.

66 For example, see Mason Durie's te whare tapa whā model, Rose Pere's te wheke model, and the work of the Eru Pōmare Centre at the University of Otago.

67 For example, see Alison Bashford, Imperial Hygiene: A Critical History of Colonialism, Nationalism, and Public Health (New York: Palgrave MacMillan, 2004). 
(such as the sterilisation of indigenous populations) horrify contemporary public health academics and practitioners, historically they have utilised the language of public health as their justification.

Further, as Johan Mackenbach observes, the large-scale altruism of public health has a tendency to miss or even justify particular consequences (such as the impact on individuals with genetic disorders from projects such as population-based screening) and to undermine individual autonomy. ${ }^{68}$ In its pursuit of populationwide interventions in societies that marginalise or oppress certain groups, public health has the potential to work towards 'the greatest happiness' at the expense of people and populations that are already undermined. A focus on minimising inequalities can work against this. However, even within this progressive focus lies potential for the 'ambivalent helper' trap, in which predominantly privileged public health academics and practitioners grapple with how to 'do' health improvements, without 'doing to' oppressed groups. As Emma Kowal and Yin Paradies note: 'Practitioners who seek to escape neo-colonialism must inhabit only the discursive space of public health congruent with self-determination, leaving them in a bind common to many postcolonial situations. They must relieve the ill-health of indigenous people without acting upon them' ${ }^{69}$

Kaupapa Māori research can work against these traps by insisting on the integrity of process and paying heed to a wider worldview than conventionally considered by the spe-

68 Johan Mackenbach, 'Kos, Dresden, Utopia . . . A Journey Through Idealism Past and Present in Public Health,' European Journal of Epidemiology 20 (2005): 817-826. This relationship is not as simple as some critics of public health would argue. For example, a public health initiative which restricts the advertising of tobacco products may be seen to be restricting people's individual choice. However, it is also restricting the ability of tobacco companies to manipulate people and therefore frees individuals from the influence of marketing.

69 Emma Kowal and Yin Paradies, 'Ambivalent Helpers and Unhealthy Choices: Public Health Practitioners' Narratives of Indigenous Ill-health,' Social Science and Medicine 60 (2005): 1347. 
cialisation of disciplines. ${ }^{70}$ It is not inherently transdisciplinary, nor should transdisciplinarity pluck convenient elements from Kaupapa Māori methodology. Rather, when importing a concept into Aotearoa New Zealand, it is salient to consider what already exists that speaks to the same concepts, and to consider how we might invest in Indigenous ideas before we implant a new one. Transdisciplinarity stems from the same sets of concerns about disciplinarity that partially drives Kaupapa Māori research. However, it still comes out of a Western framework. Consequently, as well as considering how theoretical concepts like transdisciplinarity can enrich our work, we also need to consider whether there are ways in which the application of transdiciplinarity might undermine Kaupapa Māori research. Nevertheless, there appears to be the potential for fruitful partnering and the challenge lies with those who work in fields that remain committed to certain types of knowledge to open themselves to new ways of thinking and doing that may better serve holistic, sensitive, and collaborative action on climate change.

\section{Conclusion}

The public health-art interface is compelling, but the nature of this nexus isn't yet well imagined. Nor is its radical potential explored, particularly with regard to public health and the variety of wicked problems it faces. In creating a vital space for the imaginative 'leap of faith' required for radically innovative thinking to occur, a transdisciplinary approach offers the potential for more effective and imaginative action on wicked problems. While we have chosen to focus on the potential relationship between

70 For example, see Tuhiwai Smith, Decolonizing Methodologies, 130. 
art and public health, this is possible between many different disciplines, communities, and projects. This paper has explored some elements of what a genuine and productive partnership needs and what these types of partnerships need in the context of the wicked problem of climate change. To meet these challenges, public health has radical potential, yet it remains committed to the paradigm of scientific knowledge and questioning. As Anne Noble argues, 'art has an imperative to ask some parallel but different questions that draw on our sensory and imaginative capacity to fully comprehend the impact of human action on natural biological systems'. ${ }^{71}$ By engaging with a diverse set of skills, tools, and strategies, transdisciplinary engagement can potentially foster novel ways of thinking and doing that render us better able to respond to complex, and at times unpredictable, challenges. 
If you like what you have read, please subscribe or donate.

\author{
G \\ COUNTERF UTURES \\ Left thought \& practice Aotearoa \\ (C) Copyright Counterfutures 2018
}

